\title{
Demand for Financial Service in Capital Market of Nepal
}

\author{
Ajaya Dhungana ${ }^{1 *}$, Tej Prasad Devkota ${ }^{2}$
}

1 Assistant Director, Securities Board of Nepal (SEBON), Lalitpur, Nepal

2 Director, Securities Board of Nepal (SEBON), Lalitpur, Nepal

* Corresponding Author (dh.ajaya@gmail.com)

Received: 25 May, 2021

Revised: 28 August, 2021

Accepted: 10 November, 2021

Published: 25 December, 2021

How to cite this paper:

Dhungana, A. \&, Devkota, T.P. (2021). Demand for financial service in capital market of Nepal. Quest Journal of Management and Social Sciences, 3(2), pp. 162-174.

Copyright (C) 2021 by authors and Quest Journal of Management and Social Sciences.

This work is licensed under a Creative Commons Attribution-Non Commercial-No Derivatives 4.0 International License.

https://creativecommons.org/ licenses/by-nc-nd/4.0/

\section{Abstract}

Background: In the contemporary literature, access to finance is well spell-out as the key to development. The supply leading hypothesis asserts that financial deepening contributes to enhancing growth so, the growth of the financial market is regarded as an important infrastructure to influence saving and investment. The Government of Nepal opted for a policy 'One person one bank account' in its fiscal policy in 2018/19 (MOF, 2018). Aligning the policy, the Securities Board of Nepal (SEBON) launched the 'one Nepali one D-mat account' policy in 2018 to increase the access of the capital market throughout the country. The low-financial literacy base is a major constraint to develop the market, in the other, most of the rural population, still are not equipped with the capital market instrument. In, this background, there is an utmost need to examine the factors contributing the demand for the financial services.

Objective: The primary objective of the study is to access the determinants of the demand for financial services in the capital market of Nepal, considering the supply leading hypothesis.

Method: To examine the determinants of the demand for financial service, we employed the Ordinary Least Square method of regression analysis. The dependent variable employed in this study is the demand for financial services. Level of income, access to finance and financially active provinces have been taken as the independent variables along with the concerned district population. As well, the financial literacy program conducted by the capital market regulator is another major independent variable.

Result: Through the demand following hypotheses asserts that financial literacy is the key to influence the demand for financial services. It is found that financial literacy programs conducted by the capital market regulator could not explain the demand for financial services in Nepal indicating the weak performance of the program conducted by SEBON. It is found that the number of BFIs, population and financially active provinces are highly significant with the demand for financial services indicating the influential role of supply leading hypothesis.

Conclusion: The study concludes that the variables selected to determine the demand for financial services in capital market are appropriate and most of them (population, per capita income, financially active provinces and access to financial services) are significant with the capital market of Nepal. It is observed that the financial literacy programs conducted by the capital market regulator have not contributed in enhancing demand of the financial services in the capital market of Nepal.

Recommendation: The study is focused and based on the capital market of Nepal. Results obtained from this study could not replicate the same in the money market or insurance sector of Nepal. The findings of the study strongly recommend the regulatory body to evaluate and revise its financial literacy programs while in the meantime urge to focus on addressing demand-side inefficiencies in the long run.

Originality: The research work is original and has not been published in other publications. As well, no financial support has been received for the study.

Paper Types: Research Paper

Key Words: Financial literacy, financial accessibility, financial instruments, stock market participation.

JEL Classification: G19, G53 


\section{Introduction}

The development of the financial sector is widely recognized as an important determinant of the economic growth of any country. The financial planning and policies for the development of the financial sector in Nepal have been formulated from the supply-side perspective. An increase in the accessibility of the financial service is the major concern among the financial market regulators of Nepal. The central bank (Nepal Rashtra Bank) urged the commercial banks to establish at least one branch in all (753) local bodies of Nepal. The purpose of such a policy is to increase the accessibility of banking services to the citizens of Nepal. On the other hand, the capital market regulator, the SEBON also initiates the policy to have a Dematerialized account of every Nepali citizen with the slogan "One Nepali, One D-mat" (SEBON, 2018). The purpose of such a policy adopted by SEBON is to increase public participation in the capital market.

Over the years, the development of the stock market in Nepal has been slow in pace. NEPSE formally started operation in 1993 and several surpassed various changes under the act. The existing open-outcry trading system was replaced with a semi-automated screen-based trading system in 2007 and since then, has undergone various changes. A full-fledged automated trading system has been started on 15 th January 2016 after the implementation of dematerialized trading in securities. In the last few years, the Nepalese capital market has made remarkable progress in terms of participation in the primary as well as in the secondary market. After the implementation of the ASBA system, the access of the primary market is spread out all over the country and at the same time, people can access the secondary market from everywhere in the country online through their gadgets.

The theory of the stock market participation puzzle was initiated by Haliassos and Bertaut (1995). The researcher analyzed why the majority of the US household do not invest in the stock despite the equity premium and prediction of an expected utility model. With this theoretical ground. the motivation behind writing this paper arose from two reasons; the first one is, increased financial access to every nook of the country. In the last few years, the Nepalese financial sector has been well spread out throughout the country. The number of accounts maintained in the BFIs has been increasing significantly. On the other, the tendency of credit avail is increasing interestingly. The second is the ever-increasing participation of the investors in the capital market. After the implementation of the ASBA in an initial public offering, there is a tremendous increase in the number of applicants in the IPO. At the same time, the increased number of IPO applicant contribute to an increase in the number of participants in the secondary market too. Observing the scenario, the question triggered what are the determinants that contribute to the increasing demand for financial services in the financial market? Is there a nexus among the financial access and demand for financial service? or what else? Thus, the objective of the study is to examine the determinants of the demand for financial services in Nepal.

The introduction section of the study is followed by a literature review. In the next section, the study deals with research methods applied followed by the result and findings and the last section includes discussion, conclusion and policy recommendation.

\section{Review of Literature}

Stocks are complex financial assets, so only a few people participate in the capital market. So, this area hasn't been well explored in the literature (van Rooij, Kool, \& Prast, 2007). It is still a puzzle why so many households do not hold stock (Campbell, 2006). However, investment in the stock market, taking a loan, or planning retirement savings are the basic examples of core financial decision and various studies show that these decisions are significantly correlated with individuals' financial literacy (van Rooji, Lusardi, \& Alessie, 2011; Gaudecker 2015; Lusardi \& Tufano, 2015). Furthermore, the speed at with an individual adopts the financial innovation also has been discussed by Bauer and Hein (2006) for the likelihood of holding the stock. 
Cole, Sampson, and Zia (2009) surveyed financial literacy, financial decision and the demand for financial services for India and Indonesia. Using the survey data, the study explored financial literacy as a powerful predictor for demand for financial services. Further, the researchers conducted a field experiment offering an incentive to the randomly selected households to open a bank account intending to test the relative importance of financial literacy and incentives. They claimed that financial literacy has no effect on the likelihood of opening a bank account but subsidy has a large effect on illiterate households. The study concluded that financial literacy has a great impact on a personal level. If individuals save more and manage risk better, there may be general equilibrium effects by increasing demand by the households for financial services. Ultimately, it improves risk-sharing, reduces economic volatility, improves intermediation and speed over financial development that contributes to fair competition in the financial sector and more efficient allocation of resources in society.

Demand for financial service in the banking sector is indexed by the total number of bank accounts, total number of loan accounts, total number of debit/credit cards issued, number of mobile/internet banking users, etc. Furthermore, the demand in the insurance sector is indexed by the number of life insurance, health insurance, term insurance and other kinds of insurance policies issued. However, in the capital market, the demand for financial services can be measured by either the number of participants in the primary market or by the number of participants in the secondary market. The first hypothesis of the study is;

\section{H1: Demand for financial service in the capital market of Nepal is positively affected by the district population.}

Wamwayi Inganga, Njeru, Ombui, and Tirimba (2014) examined the factors affecting customer demand for financial services offered by commercial banks in Nairobi. The study found that levels of income and savings are crucial for long-term financial services whereas the cost of financial transactions does not deter consumers from availing of financial services. It is concluded that the higher the income the higher the ability to access more and better financial services. The second hypothesis of the study is;

\section{H2: The income level has a positive relationship with the demand for financial services in the capital market of Nepal.}

Königsheim, Lukas, and Nöth (2017) surveyed more than 1700 customers of a German bank to explore the determinants of demand for digital financial services in Germany. The study explores that financial knowledge and risk preference could explain a large part of the financial decisions made by the households compared to gender, age, and education. The study further reported that financial knowledge and risk tolerance have a significant and positive correlation with the demand for digital financial services.

Timsina (2017) examined the determinants of commercial bank lending in Nepal using the Ordinary Least Square (OLS) regression approach for the period of 1975-2014. The study claimed that gross domestic product (GDP) and liquidity ratio have the greatest impacts on lending behaviors. Furthermore, the researcher observed a unidirectional relationship from GDP to private sector credit. Hence, from the above-stated literature, per-capita income is another important variable that determines the demand for financial services. The third hypothesis of the study is;

\section{H3: The accessibility of financial services has a positive relationship with the demand for financial services in the capital market of Nepal.}

The participation of the public in the financial market, especially in the capital market, in Nepal is low. This indicates that the demand for financial services in the financial market in developing countries like Nepal is low. There have been extremely few studies regarding the demand for financial services. As of today, the researcher didn't find any studies regarding the demand for financial services in the capital market of Nepal. The objective of this research is to examine the relationship and degree of associations of various variables determining the demand for financial service in the Nepalese capital 
market. In the context of Nepal, the asymmetric distribution of the financial services has made some provinces financially active and some others passive. To test this statement, the fourth hypothesis of the study is;

\section{H4: The financially active province demands higher financial service in the capital market of Nepal.}

Ramlall (2014) conducted a large household survey in Mauritius to identify whether there is a pecking order in demand for financial service. The financial services were categorized into the bank account, mobile banking, shares, life assurance and treasury bills. Shares represent the services of the capital market. The researcher used a distinct financial literacy questionnaire to associate the linkage of financial literacy with financial services. Financial literacy, net saving per capita, expenditure per capita, marital status, bank loan, age, culture, gender, schooling, risk aversion, fatalism, poverty were the variables used in the matrix to identify the pecking order in demand for financial services. The fifth hypothesis of the study is;

\section{H5: The financial literacy program has a positive relationship with the demand for financial services in Nepal.}

According to Peachey and Roe (2006), the increased access to financial services enables the lowincome family to enhance and diversify their earning; improves their life standard by improving the social and economic conditions which are reflected through the multi-dimensional aspect of poverty. The researcher has also observed that only a limited number of people would access formal financial services in low-income countries. For example, in developed countries such as Germany and Denmark 96.5 and 99.1 percent population have access to financial services respectively, whereas the percentage in low-income countries such as Kenya and Ghana is less i.e., only 10 percent (Pesaresi and Pilley, 2003 as cited by Akpandjar, Quartey, \& Abor, 2013).

Soedarmono and Prasetyantoko (2017) surveyed 4000 households in different four cities of Indonesia employing the probit-logit technique to understand the relationship between financial literacy and bank credit demand. The results revealed that individuals with higher financial literacy are associated with higher demand for bank credit. Moreover, they claimed that individuals with higher financial literacy also tend to have formal saving accounts.

Klapper and Lusardi (2019) measured financial literacy using questions assessing basic knowledge of four fundamental concepts in financial decision-making: knowledge of interest rates, interest compounding, inflation, and risk diversification. Research suggests that financial inclusion can help drive positive development outcomes. But if people lack the knowledge to effectively use financial skills, these opportunities can instead lead to negative outcomes, such as high indebtedness. This is especially true for women, the poor, and the less educated, all of whom suffer from low financial literacy.

Jha and Shayo (2021) experimented with a classroom setting to assign individuals incentives, opportunities and nudges to trade in actual financial assets. The experiment was conducted over a pool of individuals, consisting of 60,000 participants in Israel. The research design indicates a potentially fruitful way to achieve the goals, ever among time-constrained and hard to recheck working-age populations. The study claimed that financial literacy was key in trading financial assets and more standard education program has increased financial literacy.

In this regard, this paper examines the plausible views that could explain the demand for financial services in the capital market of Nepal. As far researcher's knowledge is concerned, there has been no such empirical study to date in Nepal that explains the demand for financial service specifically in the capital market of Nepal. 


\section{Research Methods}

The positivist approach has been adopted to investigate and analyze the research question. The research has been conducted by using the cross-sectional data of the year 2019. The secondary source of data, which has been taken from various sources such as Dematerialized accounts from CDS and Clearing Limited, population data from Central Bureau of Statistics, BFI data from Central Bank, financial literacy program data from the SEBON, has been used in the research. Furthermore, the researcher has made the operational definition for the financially active provinces, which has been treated as the dummy variable. The districts of Nepal have been used as the unit of data. Before the promulgation of the New Constitution in September 2015, there were 75 districts. The New Constitution has separated Nawalparasi and Rukum districts into two parts and the number of districts reached 77 in total. However, due to the non-availability of data from newly formed districts, these two districts have been treated as a whole district. So, the total number of observations remained 75. EViews 10 has been used to perform the statistical operation.

\section{Specification of variables}

i. Demand for financial services: This is the dependent variable of the study. Since the study concentrated on the capital market, the demand for financial services has been measured by public participation in the secondary market. The number of public participations in the secondary market can be obtained through the number of Dematerialized accounts (D-mat a/c). The D-mat a/c is one of the essential elements to participate in the capital market. This is an electronic location where the securities can be stored. The CDS and Clearing Limited maintain the record of D-mat a/c, so the data has been abstracted from the CDS and Clearing Limited. Furthermore, the data has been filtered to remove the D-mat a/c of institutions, so that the data only contains information about natural persons. The log-transformed data of D-mat a/c has been used for the research calculation. Kozak and Sosyura (2015) used the brokerage account as the proxy to measure the participation in the capital market, whereas holding of the stock has been used as the proxy of the financial market participants in the previous study (Saunders, 2015).

ii. Population: Population is one of the independent variables of the study. Since the unit of data of this study is the district, the population of districts has been taken from the data published by the Central Bureau of Statistics (CBS). A higher number of populations demands a higher level of financial services is the prior expectation with this variable.

iii. Income: The prior expectation of the relation between income and demand for financial service is positive. Several studies have used income as the explanatory variable to define financial market participation (van Rooij, Lusardi, \& Alessie, 2011; Changwony, Campbell, \& Tabner, 2015; Kadoya \& Khan, 2020). A higher-income population demands a higher level of financial service in the capital market as an investment is made from the saving amount in the economy. The per capita income (PCI) of the district has been used to capture the income, this has been taken from the database of CBS. The PCI is the average earning of the resident of a particular place.

iv. Accessibility to financial service: Generally, the number of banks and financial institutions (BFI), the number of Automated Teller Machine (ATM) or Cashpoint, extension counters of BFI, and the number of branchless banking service is summed up to calculate the accessibility to financial service. However, for this study, only the number of branches of BFI has been considered, since most of the BFI branches either provide the Application Supported by Blocked Amount (ASBA) service for primary market or Depository Participant (DP) service for the operation of D-mat $\mathrm{a} / \mathrm{c}$ or both, these are the services related with the capital market. So, the number of ATMs, extension counters and branchless banking services has been excluded in this study. Kozak and 
Sosyura (2015) have used the accessibility to financial services as an explanatory variable to determine stock market participation.

v. Financially active province: The province where the capital of the federal state lies has been taken as a financially active province. This province includes most of the federal government offices and the districts in the province are closely linked with the capital. Changwony et al. (2015) used the government region area as the explanatory variable to define the stock market participation. The Bagmati Province of Nepal has been considered as the financially active province because the securities brokerage facilities are highly concentrated in this province so that the investors in this province have higher accessibility to participate in buying and selling process of securities. This has been treated by using a dummy variable; if the district lies in Bagmati Province then the district will be coded as 1 if not 0 . The prior expectation with a financially active province is a positive relationship with the dependent variable.

vi. Financial literacy program: Several studies have shown the importance of financial literacy (Almenberg \& Dreber, 2015; Lusardi \& Mitchell, 2017; Sivaramakrishnan, Srivastava, \& Rastogi, 2017) in financial market participation. Financial regulators have been actively involved in various programs to enhance the financial literacy of the public. To observe the effect of such financial literacy program a dummy variable is inserted. The districts where the financial literacy program has been conducted in the year 2019 are coded as 1 if not 0 . Since the study aims to observe the demand for financial services in the capital market of Nepal, only the financial literacy and training programs conducted by the Securities Board of Nepal have been considered.

\section{Empirical Model}

The following model has been proposed to estimate the demand for financial services in the capital market of Nepal. The general model for the study is as follows;

Demand for Financial Services $=\mathrm{f}$ (Population, Income, Financial Accessibility, Financially Active Province, Financial Literacy Program)

$$
\text { Dmat }=f(\text { Pop }, P C I, B F I, F A P, \text { FinLit })
$$

Further, the linear regression model in the econometric form is presented below;

LnDmat $_{j}=\alpha_{j}+\beta_{1}$ LnPop $_{j}+\beta_{2} L_{n P C I_{j}}+\beta_{3}$ BFI $_{j}+\beta_{4} F A P_{j}+\beta_{5}$ FinLit $_{j}+\epsilon_{j} \ldots$ (i)

Where,

$\mathrm{LnPop}_{\mathrm{j}}$ indicate log of the population of $\mathrm{j}$ district.

$\mathrm{LnPCI}_{\mathrm{j}}$ indicate the log of per capita income of $\mathrm{j}$ district

$\mathrm{BFI}_{\mathrm{j}}$ indicate the number of banks and financial institutions available at $\mathrm{j}$ district

FAP $_{\mathrm{j}}$ is a binary variable which is treated as the province is financially active,

for this study, FAP is 1 for Bagmati Province and 0 for other

FinLit $_{j}$ is a binary variable, which represents that financial literacy program has

been conducted in a j district. The value is 1 if such a program has been conducted

in $\mathrm{j}$ district, otherwise 0 .

\section{Data Analysis and Result}

\section{Descriptive Statistics}

Table 1 shows the descriptive statistics of the variable under study i.e., the mean, median, standard deviation, skewness and kurtosis of the data. 


\begin{tabular}{lcccc}
\hline \multicolumn{4}{c}{ Table 1: Descriptive Statistics } \\
\hline DMAT & PCI & POP & BFI \\
\hline Mean & 20765.96 & 1081.240 & 353260.1 & 66.14667 \\
Median & 10904.00 & 1007.000 & 261770.0 & 42.00000 \\
Maximum & 318925.0 & 3166.000 & 1744240. & 793.0000 \\
Minimum & 468.0000 & 487.0000 & 6538.000 & 5.000000 \\
Std. Dev. & 38948.79 & 443.9742 & 283867.0 & 101.4003 \\
Skewness & 6.200837 & 2.221214 & 1.942589 & 5.248155 \\
Kurtosis & 47.23489 & 10.27731 & 9.045798 & 36.66848 \\
Jarque-Bera & 6595.397 & 227.1701 & 161.3946 & 3886.684 \\
Probability & 0.000000 & 0.000000 & 0.000000 & 0.000000 \\
Sum & 1557447. & 81093.00 & 26494504 & 4961.000 \\
Sum Sq. Dev. & $1.12 \mathrm{E}+11$ & 14586366 & $5.96 \mathrm{E}+12$ & 760869.4 \\
Observations & 75 & 75 & 75 & 75 \\
\hline
\end{tabular}

For descriptive statistics, the data has been processed before the log transformation of the data. The Jarque-Bera (JB) test statistics are used for testing the normal distribution of the data series, the small probability of the JB failed to reject the normal distribution of the data.

\section{Correlation analysis}

\begin{tabular}{cccccc}
\hline \multicolumn{5}{c}{ Table 2: Correlation Matrix } \\
\hline LnPop & LnPCI & BFI & FAP & FinLit & \\
\hline 1.0000 & -0.1019 & 0.5338 & 0.1080 & 0.2243 & Pop \\
& 1.0000 & 0.4530 & 0.3205 & 0.2457 & PCI \\
& 1.0000 & 0.2714 & 0.3524 & BFI \\
& & 1.0000 & 0.1221 & FAP \\
& & & 1.0000 & FinLit \\
\hline
\end{tabular}

Table 2 shows the correlation matrix between the variables. The degree of correlation between population and bank and financial institutions seems to be high, so multicollinearity can be suspected which will be further cleared by the Variance Influence Factor (VIF) test for detection of multicollinearity. There is a negative correlation between per capita income and population, which is as expected, that per capita income decreased with the increase in population. The correlation between the rest of the variables is positive. To further confirm the collinearity problem, the result of Variance Influence Factor (VIF) has been observed. VIF is calculated as:

$$
V I F(j)=\frac{1}{\left(1-R(j)^{2}\right)}
$$

...where, $R(j)$ is the multiple correlation coefficient between variable $j$ and the other independent variables. The result of VIF has been presented in Table 3 . 


\section{Table 3: Variance Inflation Factors}

\begin{tabular}{ll}
\hline LnPop & 1.739 \\
LnPCI & 1.713 \\
BFI & 2.260 \\
FAP & 1.145 \\
FinLit & 1.167
\end{tabular}

The result of VIF shows no collinearity between the variables. The result of VIF is less than 2, which further confirms that no multicollinearity problem exists between the variables. The result suggests that with no collinearity problem, the regression can further proceed ahead.

\section{Regression Analysis}

\begin{tabular}{|c|c|c|c|c|}
\hline \multicolumn{5}{|c|}{ Table 4: OLS, Dependent variable: LnDmat } \\
\hline \multicolumn{5}{|c|}{ Heteroskedasticity-robust standard errors, variant HC1 } \\
\hline & Coefficient & Std. Error & t-ratio & p-value \\
\hline const & -13.0121 & 2.41297 & -5.393 & $<0.0001 * * *$ \\
\hline LnPop & 1.01340 & 0.101419 & 9.992 & $<0.0001 * * *$ \\
\hline LnPCI & 1.35656 & 0.222926 & 6.085 & $<0.0001 * * *$ \\
\hline BFI & -0.00143656 & 0.000589587 & -2.437 & $0.0174 * *$ \\
\hline FAP & 1.15151 & 0.206076 & 5.588 & $<0.0001 * * *$ \\
\hline FinLit & 0.355870 & 0.187011 & 1.903 & $0.0612^{*}$ \\
\hline Mean dependent var & 9.183351 & & S.D. dependent var & 1.300048 \\
\hline Sum squared resid & 24.57374 & & S.E. of regression & 0.596776 \\
\hline R-squared & 0.803519 & & Adjusted R-squared & 0.789281 \\
\hline $\mathrm{F}(5,69)$ & 125.8345 & & P-value(F) & $2.91 \mathrm{e}-33$ \\
\hline Log-likelihood & -64.57752 & & Akaike criterion & 141.1550 \\
\hline Schwarz criterion & 155.0600 & & Hannan-Quinn & 146.7071 \\
\hline
\end{tabular}

Table 4 shows the regression analysis of the model mentioned above. It has been conducted by using the method of Ordinary Least Square (OLS) Heteroscedasticity - robust standard error. The reason behind performing the OLS with white standard error is that the error term of the simple OLS violates the assumption of homoskedasticity. The residuals of the regression above are free from heteroskedasticity (see Table 5). The result of the regression analysis shows that the overall model fit adjusted $\mathrm{R}$ square is 0.7892 , which indicates that the dependent variable is explained 78.92 percent by the regressors. Moreover, three independent variables, namely Pop, PCI, FAP, are found to be significant at a 1 percent level of significance. BFI is significant at a 5 percent significance level and FinLit is found to be insignificant at a 5 percent level of significance. However, the variable is found to be significant at a 10 percent level of significance.

The coefficient of all of the independent variables except BFI is positive. The negative coefficient of BFI indicates that there is a negative relation between the increased financial accessibility and demand for financial services. This result fails to accept hypothesis H3. However, the coefficient of BFI is only -0.0014 , so the degree of association is very low. This result contradicts the finding of Kozak and Sosyura (2015). The coefficient of the population is positive and also significant at a 1 percent significance level, there is also a high degree of association between the population and demand for 
financial service. This result supports hypothesis H1. Furthermore, the coefficient of per capita income is also positive and significant at a 1 percent significance level. The result of the income supports the findings from the previous study of Kadoya, Khan, and Rabbani (2017). There is also a high degree of associations between PCI and D-mat a/c, this result supports hypothesis $\mathrm{H} 2$.

The dummy variable FAP is also significant at a 1 percent significance level. This result indicates that the Bagmati Province of Nepal demands a higher level of financial service. The finding of the study is similar to the findings of Changwony et al. (2015). The coefficient of FAP indicates there is a high degree of association and it also supports hypothesis H4. Another dummy variable financial literacy program (FAP) conducted failed to be significant at a 5 percent level of significance. There is also a moderate degree of association between the financial program conducted and the demand for financial services. The result from Cole, Sampson and Zia (2011) shows that the education program has a modest effect on simulating demand for bank accounts among uneducated and less financially literate families. This study shows similar results in the capital market sector as well, where the financial literacy program has been conducted. However, the result fails to accept hypothesis H5 at a 5 percent level of significance.

\section{Heteroskedasticity Test}

Two tests have been conducted to check the heteroskedasticity of the residuals of the model. According to White's test for heteroskedasticity (squares only), the test statistics show that the value of LM is 9.54 with a P-value of 0.54 . The result failed to reject the null hypothesis which has the assumption of homoscedasticity, which indicates that the model is free from heteroskedasticity. According to the Breusch-Pagan test for heteroskedasticity, the test statistics show that the value of LM is 3.10 with a P-value of 0.68 . The result failed to reject the null hypothesis which has the assumption of homoscedasticity that indicates there is no problem of heteroskedasticity in the model. Both of the tests of heteroskedasticity are consistent and show that the model does not have the problem of heteroskedasticity. This result is presented in Table 5.

\section{Table 5: Heteroskedasticity Test}

White's test for heteroskedasticity (squares only) -

Test statistic: $\mathrm{LM}=9.54572$

with p-value $=\mathrm{P}($ Chi-square $(8)>9.54572)=0.298368$

Breusch-Pagan test for heteroskedasticity -

Test statistic: $\mathrm{LM}=3.10908$

with p-value $=\mathrm{P}($ Chi-square $(5)>3.10908)=0.683174$

Regression diagnostic is used to evaluate the model assumptions and it also investigates whether or not the observation with large, undue influence on the analysis. To further validate the model assumptions, the following test has been conducted in this study.

Normality Test and Q-Q Plots

The Jarque Bera normality test suggests that the residuals are normally distributed. The test failed to reject the null hypothesis which has the assumption that the residuals are normally distributed. The P-value of the test statistics is 0.09 , which fails to reject the hypothesis at a 5 percent level of significance. However, the null hypothesis can be rejected at a 10 percent level of significance. The result shows that the residuals are not in the perfect normal distribution.

Quantile - Quantile plots (Q-Q plots) are of two quantiles with each other. A quantile is a fraction where residual values fall below that quantile. The purpose of Q-Q plots is to find out if two sets of data come from the same distribution. A 45-degree angle is plotted on the Q-Q plots: if the two data sets come 
from a common distribution, the points will fall on that reference line. The result shows that most of the values of residual fall around the line. Q-Q plots. Furthermore, the Q-Q plots show that there are nominal extreme values in the data. ${ }^{1}$

\section{Table 6: Normality Test}

Null hypothesis: error is normally distributed

Test statistic: Chi-square (2) $=4.74279$

with $\mathrm{p}$-value $=0.0933504$

\section{Chow test}

Chow test has been conducted to confirm the structural break in the data series so that the adoption of a dummy variable is appropriate. There are two dummy variables considered in the study, the first one is Financially Active Province (FAP). The result of the Chow test suggests that there is a structural difference concerning FAP. The null hypothesis which assumes there is no significant structural difference has been rejected with a very small P-value. Furthermore, another dummy variable has also a similar result with a small (0.0011) P-value; there is a structural difference concerning the financial literacy program (FinLit). The result of the Chow test indicates that the adoption of each dummy variable is appropriate.

\section{Table 7: Chow Test}

Chow test for structural difference concerning FAP -

Null hypothesis: no structural difference

Asymptotic test statistic: Chi-square (4) $=88.2686$

with p-value $=3.0706 \mathrm{e}-018$

Chow test for structural difference concerning FinLit -

Null hypothesis: no structural difference

Asymptotic test statistic: Chi-square $(4)=18.252$

with $\mathrm{p}$-value $=0.00110171$

\section{Test for Omission of Variables}

The omitted variable test has been conducted to check whether the variables included in the regression model have to be omitted or not. Since there were very few references available to conduct this kind of study, it is necessary to examine whether the inclusion or omission of variables is appropriate or not. To conduct this test, the null hypothesis refers to the zero parameters for the variables. If the null hypothesis is accepted, then such variables have to be omitted from the regression. However, if the null hypothesis is rejected then such variables have to be included in the regression model. The result of the test of omission of variable has been reported in Table 8. It shows that the variables such as LnPop, BFI, LnPCI and FAP should not be omitted from the model. The result also shows that, regarding the variable Finlit, the null hypothesis has to be accepted at a 5 percent level of significance, which means the parameter of variable FinLit is zero. However, at a 10 percent level of significance, the null hypothesis still can be rejected leading that the variable should not be omitted. Furthermore, the result also shows that the variable FinLit along with another independent variable should not be omitted together.

$1 \mathrm{Q}-\mathrm{Q}$ plots figure is not reported in the paper. 
Table 8: Test for the Omission of Variables

\begin{tabular}{lcc}
\hline Variable to omit & F statistics & P-value \\
LnPop & 99.8451 & 0.0000 \\
BFI & 5.3968 & 0.0174 \\
LnPCI & 37.0301 & 0.0000 \\
FAP & 31.2231 & 0.0000 \\
FinLit & 3.6212 & 0.0612 \\
LnPop, FinLit & 64.3033 & 0.0000 \\
BFI, FinLit & 3.8353 & 0.0263 \\
LnPCI, FinLit & 25.9977 & 0.0000 \\
FAP, FinLit & 15.6118 & 0.0000 \\
\hline
\end{tabular}

\section{Discussion and Conclusion}

This study investigates the demand for financial services in the capital market of Nepal. The result supports that the variables such as population, number of banks and financial institutions, per capita income and financially active province are highly significant with the study so they increase the demand for financial services in the capital market of Nepal. However, BFI doesn't have a positive relationship with the demand for financial services. Such a result was not expected and is surprising. This might be the effect of the mandatory policy of the central bank to establish the branch of the BFI in all the local bodies. The establishment of BFI was likely to increase the access of the public to the capital market but such establishment was not driven from the demand side rather it was an obligatory requirement from the supply side. The result shows that such an increase in access does not necessarily increase the demand for financial services related to the capital market. One more reason behind the negative relationship of BFIs with the demand for financial services in the capital market can be the limited services of the capital market provided by the BFIs in the rural areas. This study has not considered the different quality of service provided by the BFIs in the urban and rural areas. Furthermore, the result also shows that the financial literacy program conducted by SEBON has not increased the demand for financial services in the capital market of Nepal. It is recommended that the regulatory body of the capital market should focus on an in-depth evaluation of the effectiveness of the programs for better results. The financial literacy program if can be delivered by the separate dedicated wing of SEBON can be more effective. The other financial regulators, non-regulators, private companies, Non-Government Organizations (NGO's) also conduct financial literacy programs as well. Future research may consider those entire programs conducted in the study. Also, other variables such as the literacy rate of the investor, employment rate, social class of the investor may be considered to expand the scope of this research. The review of inclusive securities allotment policy would also expand the avenues for future research.

The result of this study will be helpful to the financial regulators in evaluating and redesigning the financial literacy programs and in the enhancement of the financial services to adequately address the demand side of the financial service. The investors also can be aware of identifying the driving variables to enhance the demand for financial services, and be prone towards those variables so that the demand side of the financial service can be strengthened. Policymakers should be aware of forcing supply-side factors rather than enhancing the demand side in the financial sector of Nepal.

\section{Conflict of Interest}

Author(s) declares no conflict of interest while preparing this paper. 


\section{References}

Akpandjar, G. M., Quartey, P., \& Abor, J. (2013). Demand for financial services by households in Ghana. International Journal of Social Economics, 40(5), 439-457.

Almenberg, J., \& Dreber, A. (2015). Gender, stock market participation and financial literacy. Economics Letters, 137, 140-142. https://doi.org/10.1016/j.econlet.2015.10.009

Asgary, A., Willis, K., Taghvaei, A. A., \& Rafeian, M. (2004). Estimating rural households? Willingness to pay for health insurance. The European Journal of Health Economics, Formerly: HEPAC, 5(3), 209-215. doi: 10.1007/s10198-004-0233-6

Bauer, K., \& Hein, S. E. (2006). The effect of heterogeneous risk on the early adoption of Internet banking technologies. Journal of Banking \& Finance, 30(6), 1713-1725.

Campbell, J. Y. (2006). Household finance. The Journal of Finance, 61(4), 1553-1604.

Changwony, F. K., Campbell, K., \& Tabner, I. T. (2015). Social engagement and stock market participation. Review of Finance, 19(1), 317-366. https://doi.org/10.1093/rof/rft059

Cole, S., Sampson, T., \& Zia, B. (2009). Financial literacy, financial decisions and the demand for financial services: Evidence from India and Indonesia. working paper, 09-117, Harvard Business School. Retrieved on $7 / 23 / 2020$.

Cole, S., Sampson, T., \& Zia, B. (2011). Prices or knowledge? What drives demand for financial services in emerging markets? The Journal of Finance, 66(6), 1933-1967.

Gaudecker, H.-M. V. (2015). How does household portfolio diversification vary with financial literacy and financial advice? The Journal of Finance, 70(2), 489-507.

Haliassos, M., \& Bertaut, C. C. (1995). Why do so few hold stocks? The Economic Journal, 105(432), 1110-1129. https://doi.org/10.2307/2235407

Jha, S., \& Shayo, M. (2021). Trading stocks builds financial confidence and compresses the gender gap (No. 21-010).

Kadoya, Y., Khan, M., \& Rabbani, N. (2017). Does financial literacy affect stock market participation? SSRN Electronic Journal, (15), 1-2. https://doi.org/10.2139/ssrn.3056562

Kadoya, Y., \& Khan, M. S. R. (2020). What determines financial literacy in Japan. Journal of Pension Economics and Finance, 19(3), 353-371.

Klapper, L., \& Lusardi, A. (2019). Financial literacy and financial resilience: Evidence from around the world. Financial Management, 49(3), 589-614.

Königsheim, C., Lukas, M., \& Nöth, M. (2017). Financial knowledge, risk preferences, and the demand for digital financial services. Schmalenbach Business Review, 18(4), 343-375.

Kozak, S., \& Sosyura, D. (2015). Access to credit and stock market participation. In Ross School of Business Working Paper. https://doi.org/10.2139/ssrn.2594976

Lusardi, A., \& Mitchell, O. S. (2017). How ordinary consumers make complex economic decisions: Financial literacy and retirement readiness. Quarterly Journal of Finance, 7(3), 1-31. https://doi.org/10.1142/ S2010139217500082

Lusardi, A., \& Tufano, P. (2015). Debt literacy, financial experiences, and overindebtedness. Journal of Pension Economics and Finance, 14(4), 332-368.

Peachey, S. and Roe, A. (2006). Access to finance - what does it mean and how do saving banks foster access. Perspectives, WSBI

Ramlall, I. (2014). Is there a pecking order in the demand for financial services in Mauritius? Journal of African Business, 15(1), 49-63.

Saunders, B. (2015). Financial literacy and stock market participation. The University of Minnesota. https://doi. org/10.1016/j.jfineco.2011.03.006

SEBON (2018). Annual Report Fiscal Year 2017/18. Kathmandu, Securities Board of Nepal. 
Sivaramakrishnan, S., Srivastava, M., \& Rastogi, A. (2017). Attitudinal factors, financial literacy, and stock market participation. International Journal of Bank Marketing, 35(5), 818-841. https://doi.org/10.1108/IJBM-012016-0012

Soedarmono, W., \& Prasetyantoko, A. (2017). Financial literacy and demand for financial services in Indonesia. SSRN Electronic Journal, (January).

Timsina, N. (2017). Determinants of bank lending in Nepal. In NRB Working Paper (No. 35).

van Rooij, M. C. J., Kool, C. J. M., \& Prast, H. M. (2007). Risk-return preferences in the pension domain: Are people able to choose? Journal of Public Economics, 91(3-4), 701-722. https://doi.org/10.1016/j. jpubeco.2006.08.003

van Rooij, M. V., Lusardi, A., \& Alessie, R. (2011). Financial literacy and stock market participation. Journal of Financial Economics, 101(2), 449-472.

Wamwayi Inganga, B., Njeru, A., Ombui, K., \& Tirimba, O. I. (2014). Factors affecting customer demand of financial services offered by commercial banks in Nairobi County. International Journal of Scientific and Research Publications, 4(11), 1-25. 